\title{
LIFE-CYCLE OF PASTURE INSECTS
}

\author{
W. CotTIER \\ Entomology Division, Department of Scientific and \\ Industrial Research, Nelson
}

Summary

An account is given of the information available on the lifecycles of grass-grub (Costelytra zealandica (Wh.)), subterranean grass caterpillar (Oxycanus spp.), armyworm (Pseudaletia separata (Walk.) and Persectania aversa (Walk.)), black field cricket (Acheta commodus (Walk.)) black beetle (Heteronychus sanctae-helenae Blanch.), stem weevil (Hyperodes bonariensis Kusch.), soldier fly (Altermetaponia rubriceps (Macq.)), lucerne flea (Smynthurus viridis (L.) ) and the white-fringed weevil (Graphognathus leucoloma (Boh.)).

\section{INTRODUCTION}

THIs paper reviews the life-cycles of species of insects that damage New Zealand pasture, together with the life-cycle of one insect that is suspected of causing such damage. They are, in order of treatment: grass-grub, Oxycanus spp. (Porina), armyworm, black treatment: grass-grub, Oxycanus spp. (Porina), armyworm, black
field cricket, black beetle, stem weevil, soldier fly, lucerne flea, white-fringed weevil.

\section{GRASS-GRUB}

Costelytra zealandica (Wh.)

This native species has achieved the status of New Zealand's No. 1 insect pest because it is the major pest of our most important economic crop - grass.

The adult beetle averages $3 / 8 \mathrm{in}$. in length, and is shiny light to dark brown in colour; because of the colour it is commonly referred to as the "brown beetle". In most districts it is usually first about in October-November. It flies at dusk, and, in infested grassland, the beating of the wings on the grass blades as the insect emerges from or close to the soil can be clearly heard; the insect emerges from or close to the soil can be clow droning note once the individual is properly airborne. The adult beetles feed on grasses and clovers, on the foliage of stonefruit trees and of a wide range of other plants and trees, and also on crucifers, particularly in the seed-leaf or young 4-leaf stage. In general, males emerge from pasture before females do and mating takes place before feeding occurs.

Approximately seven days after mating, the female lays her firs eggs in clusters 3 to 7 in. below the soil surface, with 3 to 40 eggs in each cluster. The average number found in a group is 22. During her lifetime the highest total number of eggs laid by one female was 52 - this was in the laboratory. There are usually intervals of time of 4 to 9 days between the laying of successive batches of eggs. Eggs are light-coloured and, with practice, can readily be seer by the naked eye. They are oval and coated with a clear stick fluid that makes them adhere closely to dry surfaces. Eggs are abli to stand fairly drastic extremes of alternate drying and wettin: without being destroyed. For development they need to be ir contact with moisture. Where moisture is adequate, eggs increas in size by absorption of water through the elastic egg membran until by the time they hatch they have increased in bulk by $25 \%$ o their original size. They take from 16 to 21 days to hatch. 

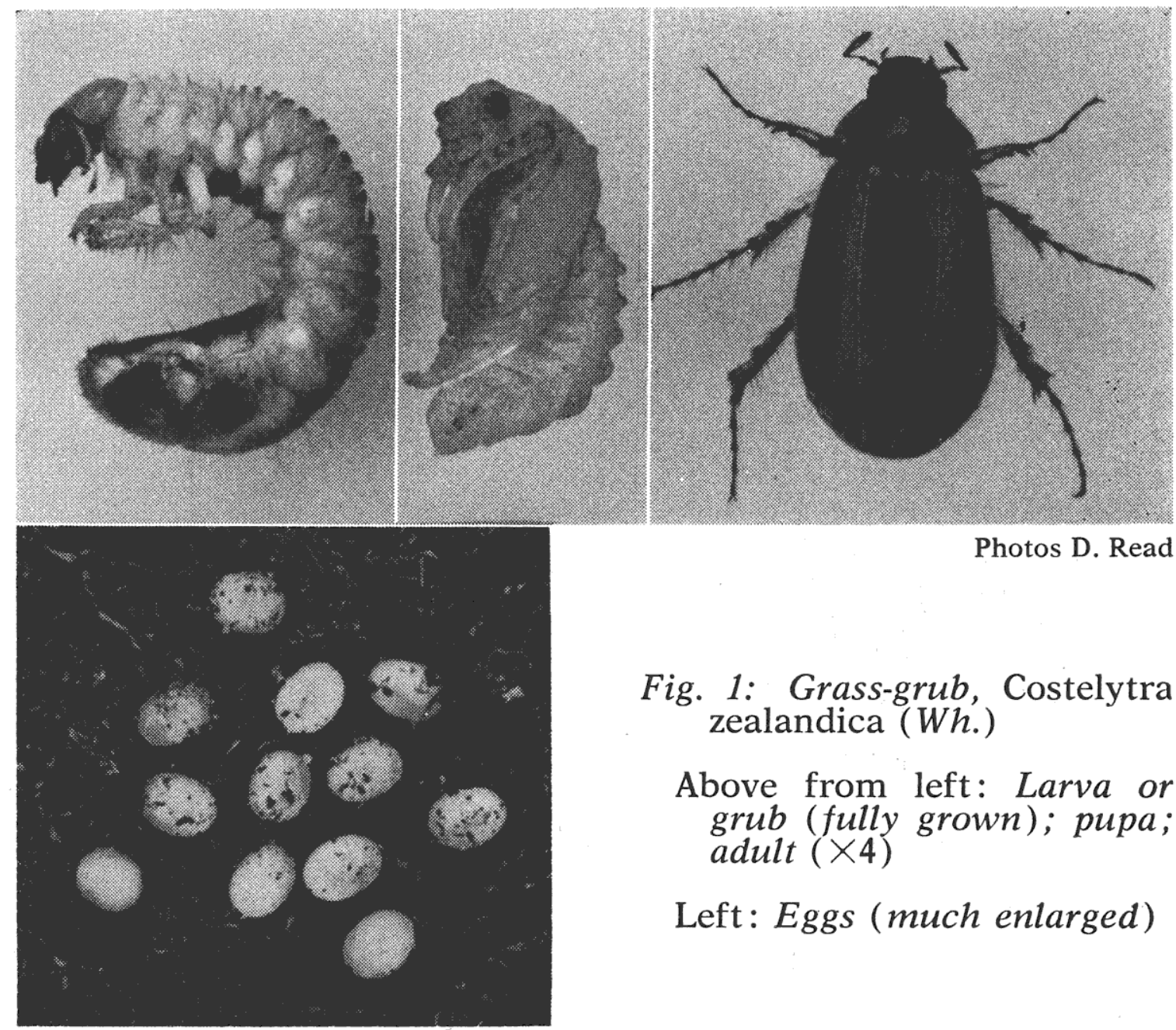

Photos D. Read

Fig. 1: Grass-grub, Costelytra zealandica $(W h$. $)$

Above from left: Larva or grub (fully grown); pupa; adult $(\times 4)$

Left: Eggs (much enlarged)

On hatching, the young larvae or grubs begin to feed almost immediately on roots in the immediate vicinity. These young grubs, which are extremely active, are crescent-shaped and white, with a brown head, six well-developed legs and a blackish hind end. They do not come above ground to feed at any stage. It is quite common in light soils to find as many as 150 grubs per square foot of infested grassland and in such heavy concentrations they destroy most of the finer plant roots below the top 2 in. of soil. After about four or five weeks (exceptionally as long as 12 weeks) the first stage larvae or instars, as they are called, cease feeding and change to the second and larger stage and in this form damage to roots becomes more marked. Second stage grubs are normally found anywhere in the top 2 in. of soil and, depending on the number per square foot, may cause the first visible symptoms of pasture damage - a patchy yellowing of top growth. Grubs spend from 5 to 10 weeks (sometimes rarely 16 weeks) in the second stage and then move down in the soil to about 3 in., where they change to the third and final grub stage. Where grub populations are high, plant roots usually have been destroyed up as far as the top inch of soil by the time the third stage is reached. This results in most third stage larvae being found in the top inch of soil where they may be seen when damaged pasture is pulled or rolled aside.

From June onwards, the oldest of the third stage larvae gradually eat less and less and their bodies become filled with yellowish fatty matter. At this stage some of them begin to move downwards in the soil until by the end of September most are below the 3 in. soil level. Though occasional larvae may enter the pupal or resting stage as early as mid-May, it is not unusual to find them in considerable numbers until the end of September and most of them become 
pupae in October. In this stage they are found from 4 to $10 \mathrm{in}$. below the surface in oval earthen cells. In the pupal stage, which lasts 4 to 6 weeks, the insect changes to the adult beetle.

When it first emerges from the pupa, the adult is cream-coloured and sluggish but it changes through golden yellow to the typical brown. Mature beetles may be found in the ground occasionally as early as July but normally they will not be numerous until October and these adults remain in the ground until about the end of the first week in November and this finishes the cycle.

The months of the year when the various stages are present are, in general, as follows:

If the peak flight occurs in mid-November, peak egg-laying might occur say in the third week of November, say November 21 . Allowing an average of 18 days for incubation, probably the bulk of eggs would be hatched by December 9 .

First instar larvae would be in the soil from December 9 to about mid-January.

Second instar larvae would be in the soil from mid-January to about early March.

Third instar larvae would be in the soil from early March to midSeptember.

Pupae would be in the soil from about the end of September to mid-November.

This cycle is generalized, as beetles have been recorded from October to January and even into February, and presumably eggs could be laid over most of this period.

\section{SUBTERRANEAN GRASS CATERPILLAR}

Oxycanus spp.

The subterranean grass caterpillar is a familiar pest to agriculturalists. The depletion of the grass cover, associated with the appearance of holes in the ground about the thickness of a lead pencil together with the presence of little mounds of earth that look like worm castings, are characteristic signs of this pest. These castings can be distinguished from those of worms by the threads of webbing through them. The damage, of course, is done by the caterpillars which, when fully grown, measure up to about $23 / 4 \mathrm{in}$. long.

There are three common species of these caterpillars that cause the great bulk of this damage in grassland throughout New Zealand. These are Oxycanus cervinatus (Walk.), O. umbraculatus (Gn.) and $O$. despectus (Walk.). Only the life-history of $O$. cervinatus is known in any detail, but as it is one of the main pests, its life-cycle is dealt with first, followed by the meagre details available on the other two species.

\section{Oxycanus cervinatus}

The moth varies from $1 \frac{1 / 4}{4}$ to $1 \frac{1 / 2}{2}$. across the outstretched wings - in some cases it may reach to a little over $2 \mathrm{in}$. The colour of the wings varies from pale brownish-black to dull yellowish-brown, and there are a number of white and black markings on the fore-wings. The pattern is very variable.

The time the adults are on the wing varies in different districts. In the Wairarapa, records have shown flight to commence in midSeptember, while in Nelson and Marlborough it commences in late September. In Canterbury and North Otago, flight may commence in early October with the peak of flight a little after the middle of the month. For Otago and Southland, flights are later still. These flights last for 20 to 30 days and the bulk of them are over by the end of October, though a few stragglers may be taken in November. It would appear from records of catches in light traps from various localities, weather records being kept at the same time, 

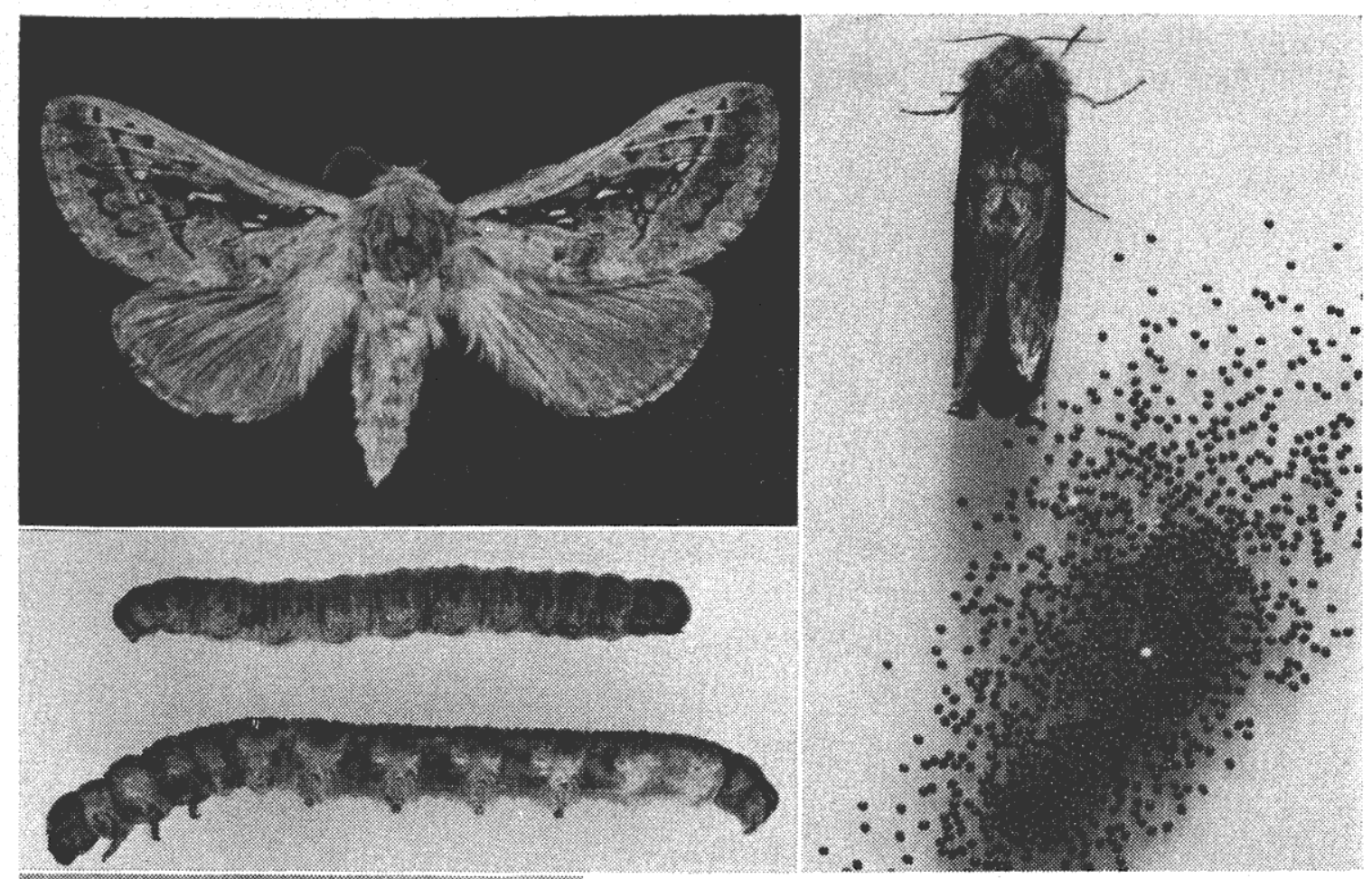

Photos D. Read

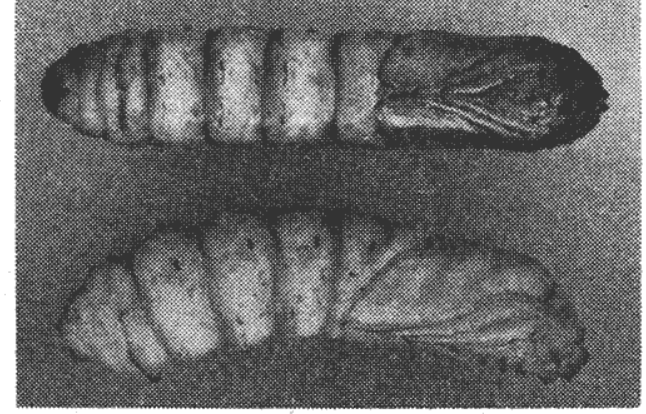

Fig. 2: Subterranean grass caterpillar, Oxycanus cervinatus (Walk.)

Left, from top: Adult $\left(\times 1 \frac{1 / 2}{2}\right)$; caterpillars (approx. natural size); pupae (natural size)

Right: Adult with eggs $\left(\times 1 \frac{1}{2}\right)$

that the main factor governing the number of moths in flight is temperature. There is evidence that largest numbers are caught following days of high temperature. The fact that high evening temperatures usually follow such days obscures the fact that temperature probably controls emergence. In fact, flight occurs on both warm and cold nights, as well as on both clear and cloudy nights and calm or windy nights. The bulk of the flight occurs during the first hour after sunset. Conditions especially favourable for flight are calmness or slight breeze and temperatures above $47^{\circ} \mathrm{F}$, especially following high day temperatures. It is probable that mating occurs on the ground shortly after emergence.

Adult females do not feed, their mouthparts being non-functional, and they thus have a short life of only 3 or 4 days.

The fertilized females lay their eggs on the ground surface or while clinging to grass leaves. It is unusual for eggs to be laid while moths are on the wing, but this sometimes occurs under abnormal conditions such as when they bump into obstructions like stones, walls, or windows. The main factor determining choice of egg-laying sites seems to be the conditions of the pastures. If they are reasonably good, most eggs are laid in the area where emergence occurs, but longer pasture ( 3 to 4 in.) seems to be preferred to pasture which has been grazed very close.

Eggs are small, oval, and creamy-white when laid but within a few hours they turn jet black. Observations have shown that one female may lay from about 450 to about 1,100 eggs. Eggs hatch in 
from 3 to 5 weeks according to the relative humidity, at the soil surface. Humidities in the range 80 to $100 \%$ permit a higher percentage to hatch and this also reduces the incubation period.

It is reported that, on hatching, the young caterpillars spend the first 4 to 6 weeks either sheltering beneath dense vegetation on the soil surface or within the top $1 / 2$ in. of soil. From January onwards they construct almost vertical tunnels in the soil to a depth of 6 to $10 \mathrm{in}$. They shelter in these during the day and come to the surface at night to feed on the pasture at or above ground level they do not eat roots except possibly when constructing tunnels. The tips of tunnels in the early stages when pasture is dense are protected by a narrow tube-like tunnel above ground. This is made of fine soil particles held together with a light webbing and is extended as food is eaten at the entrance. In time the webbing occasionally becomes almost a complete circle in severely damaged areas.

The caterpillars take an average period of 267 days to reach maturity and during this time pass through a number of stages or instars before being fully grown. This is a period of almost nine months. By the end of April or nearly May the larva has reached its full size. The period of most rapid growth is during February, March and April, with the consequence that the rate of defoliation of the pasture increases and, if a sufficiently large population is present, the pasture is completely defoliated by April.

When fully grown the caterpillars may reach up to $23 / 4 \mathrm{in}$. in length. They are rather limp and flabby when removed from the ground. Caterpillars are approaching the fully-fed state from July onwards but it is not usual for appreciable numbers to enter the resting or pupal stage until August and most reach that stage towards the end of September. Pupae are whitish at first, but soon turn a dark reddish-brown. They cannot feed but are able to move up or down tunnels in the ground and they remain in this stage for approximately six weeks. When it is time for moths to emerge pupae move to the tops of tunnels and protrude for about half their length. The moths emerge when pupal cases split longitudinally down the back.

A synopsis of the life-cycle (in Canterbury) is as follows:

Peak of moth flight $\quad . . . . . \quad$....... mid-October

Eggs hatched by $\quad$....... $\quad$........ mid-November

Caterpillars in ground $\quad . . . . . .1$ mid-November to mid-August

In pupal stage ...... ....... ....... August to October

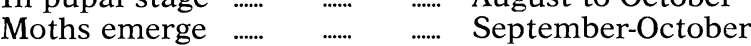

Oxycanus umbraculatus and $O$. despectus

Very little is known of the life-histories of the other two species. The appearance of the moths is, in general, very similar to that of $O$. cervinatus with, of course, some differences in colouring and markings. In $O$. umbraculatus the moth appears from October to January and the larva is said to live through the autumn and winter in burrows in the ground at a depth of 3 to $5 \mathrm{in}$. below the surface. It is distributed throughout the country.

The moths of $\boldsymbol{O}$. despectus appear from November to February, so it is a little later than the other two species, being about three months later than that of $O$. cervinatus. Caterpillars of this species are commonly present in grassland in November. The species is common in the South Island but there are records of it also from the North Island. 


\section{ARMYWORM}

There are two species present in New Zealand - the introduced cosmopolitan species Pseudaletia separata (Walk.), and the native species Persectania aversa (Walk.).

The cosmopolitan species has been known in literature as Cirphis unipuncta (Haw.) but this is a misidentification, not a synonym. The native species has been known previously by the incorrect names $P$. composita (Guen.) and $P$. ewingi Westw.

In the North Island, larval sampling shows that Pseudaletia separata, the introduced cosmopolitan armyworm, is present in Northland, South Auckland, Bay of Plenty, Poverty Bay, Hawke's Bay, Taranaki, and Wairarapa, and it is probably present in all districts. Some caterpillars of Persectania aversa have been taken from southern Hawke's Bay and from Wairarapa and it is interesting to note that light trapping shows $P$. aversa to be present in numbers throughout the North Island but it does not seem to be epidemic. It is Pseudaletia separata that is responsible for the epidemics.

In the South Island, field samples from infestations show that $P$. separata is predominant in Nelson and Golden Bay. In Marlborough both species have been taken from outbreaks; south of Nelson and Marlborough the only species recorded is Persectania aversa.
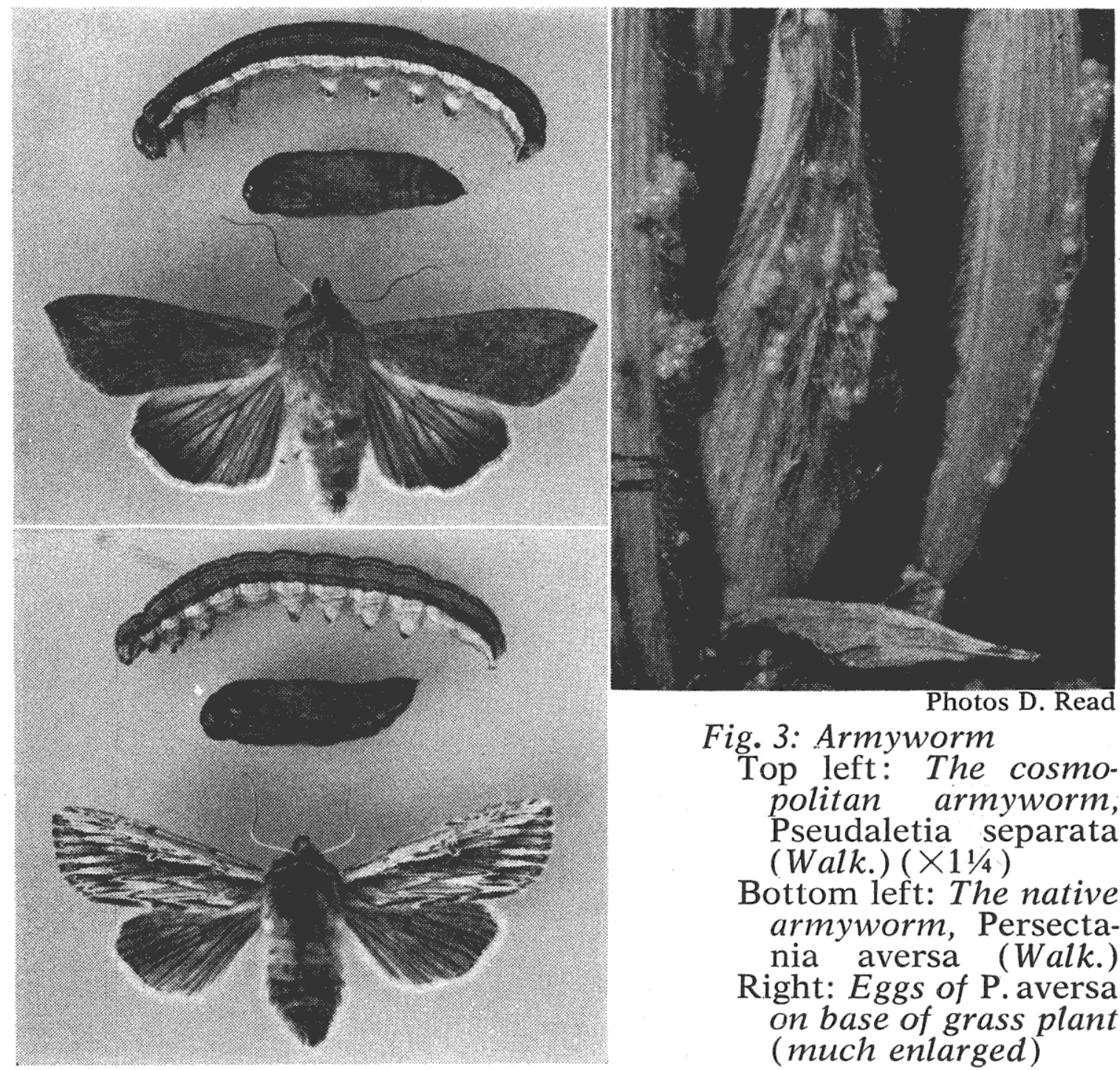

Fig. 3: Armyworm

Top left: The cosmopolitan armyworm, Pseudaletia separata (Walk.) (X11/4)

Bottom left: The native armyworm, Persectania aversa (Walk.)

Right: Eggs of P. aversa on base of grass plant (much enlarged) 
Armyworm outbreaks have been reported in New Zealand as long ago as 1895 - but they were very sporadic outbreaks. In the North Island ten years ago and earlier, outbreaks used to be reported once every three years or so in Northland, but these would disappear very rapidly. Now, however, attacks have been recorded over most districts of the North Island. Very often it is coastal regions that have been attacked, preferred areas being those with warm northern aspects and in long rank growth. There has been some change in agricultural practice that has brought about the increase in armyworm activity but what it is is not known.

It has been noted by several observers that, in the north, armyworm outbreaks seemed to occur more commonly after flooding. Observations over the last few years do indicate that caterpillars (and perhaps eggs) may be carried from large catchment areas and these are concentrated round the margins of the flood waters. Evidence from the Te Awamutu area in a season of flooding and subsequent outbreaks of armyworm suggests that the time elapsing from the recession of flood waters, February 26 , to the reports of damaging outbreaks on March 28 (this means mature caterpillars) was insufficient to allow the supposition that moths invaded the flooded areas, laid eggs, and that the damage was caused by the resulting caterpillars. It seems much more likely that partly-grown caterpillars floated down on flood waters.

\section{LIFE Cycle of Pseudaletia separata}

It is not known exactly how many eggs the adult female lays. It is certainly some hundreds and from the rearing experiments that have been made in breeding populations for insecticide testing the figure is put at round about 300 - but this is possibly by no means exact.

As far as it has been possible to ascertain, overwintering occurs mainly in the larval stage, the caterrpillars pupating in spring and giving rise to new season's moths. During the period spring to autumn it has been possible to breed three generations of the moths out-of-doors at Nelson. Details are as follows:

First generation

Date eggs laid Oct. 28,1958

Date egos hatched 11, 1958

Date of pupation ........................... Dec. 10, 1958

Date adult moths emerged ... Jan. 2, 1959

Second generation

Date eggs laid Jan. 8, 1959

Date eggs hatched ..................... Jan. 14, 1959

Date of pupation ....................... Feb. 18, 1959

Date adult moths emerged .... Mar. 8, 1959

Third generation

Date eggs laid Mar. 7, 1959

Date eggs hatched .............................. 13, 1959

Date of pupation Apr. 20,1959

Date adult moths emerged Jun. 9, 1959

Incubation period 14 days Caterpillar period 29 days Pupal period 23 days

Incubation period 6 days Caterpillar period 35 days Pupal period ............ 18 days

\section{LIFE CyCle of Persectania aversa}

As in Pseudaletia separata, the female moth lays some hundreds of eggs - each female on the average seems to lay approximately 300 .

Overwintering in this species also appears to occur in the caterpillar stage, moths emerging from pupae in the spring. The following data were secured from outside cages on ryegrass in Nelson. 
First generation

Date eggs laid

Date eggs hatched ........................... Sept. 15, 1958

Date of pupation ………........ Nov. 23, 1958

Date adult moths emerged ... Dec. 7, 1958

Incubation period 19 days Caterpillar period 69 days

Second generation

Date eggs laid Dec. 4,1958

Date eggs hatched .............................. Dec. 22, 1958

Date of pupation .................................. Jan. 28, 1959

Date adult moths emerged Feb. 24, 1959

Third generation

Date eggs laid

Mar. 1, 1959

Date eggs hatched ............................. Mar. 11, 1959

Date of pupation .................................. Apr. 26, 1959

Date adult moths emerged Jun. 16, 1959

Pupal period 14 days

It is very difficult to find eggs or young larvae produced by the generation of moths emerging in June. It appears that very few of these caterpillars get through to the spring but some do and start off the spring generation (first generation above). In both species the first generation is small, the second is the important one for damage to cereal crops and ryegrass seed crops, while the third generation is the one that damages autumn pasture. In the field there is a good deal of overlapping of generations.

\section{BLACK FIELD CRICKET}

\section{Acheta commodus (Walk.)}

Unfortunately the detailed life-cycle of this pest has not yet been fully investigated in New Zealand but what information is available on this important insect is presented here. From field observations it is apparent the life-cycle is as follows: The light-coloured (creamy) eggs are cigar-shaped, about 1/10 in. "long and in the autumn they are inserted with the ovipositor of the female into turf just below the surface of the soil. They remain unaltered throughout the winter and begin to hatch in spring from early October. The nymphs or young crickets grow and moult over a period of several months to reach maturity in late summer and in autumn (February, March and April). The small nymphs usually escape notice and it is only when they are well grown and feeding vigorously that attention is drawn to them. Crickets take refuge in cracks in the ground, and it is only on soils that crack in the summer that they appear in sufficient numbers to cause damage.

Adult crickets are black in colour, rather robust in shape, approximately $1 \mathrm{in}$. long, and the wings are folded flat on the back. The hind legs are greatly enlarged to enable the insect to hop vigorously. Females have a short sword-like ovipositor projecting from the end of the body. The immature forms or nymphs are similar to the adults except that they are smaller and the wings are undeveloped. These last appear as wing pads which become larger as the nymph becomes older.

In areas where conditions are suitable for the multiplication of the pest very serious damage may be done. On the Hauraki Plains, for example, butterfat production has, at times, been seriously hampered. Thus, on one farm that was attacked seriously for three consecutive seasons, butterfat production fell from 20,000 to $6,000 \mathrm{lb}$ per annum at the close of the period of damage and grazing had to be obtained elsewhere; in addition, resowing of damaged pasture during the three seasons cost more than $£ 800$. In 1929 some 900 acres in the Pipiroa district of the Hauraki Plains were almost completely denuded of pasture, largely as a result of damage caused by crickets. 


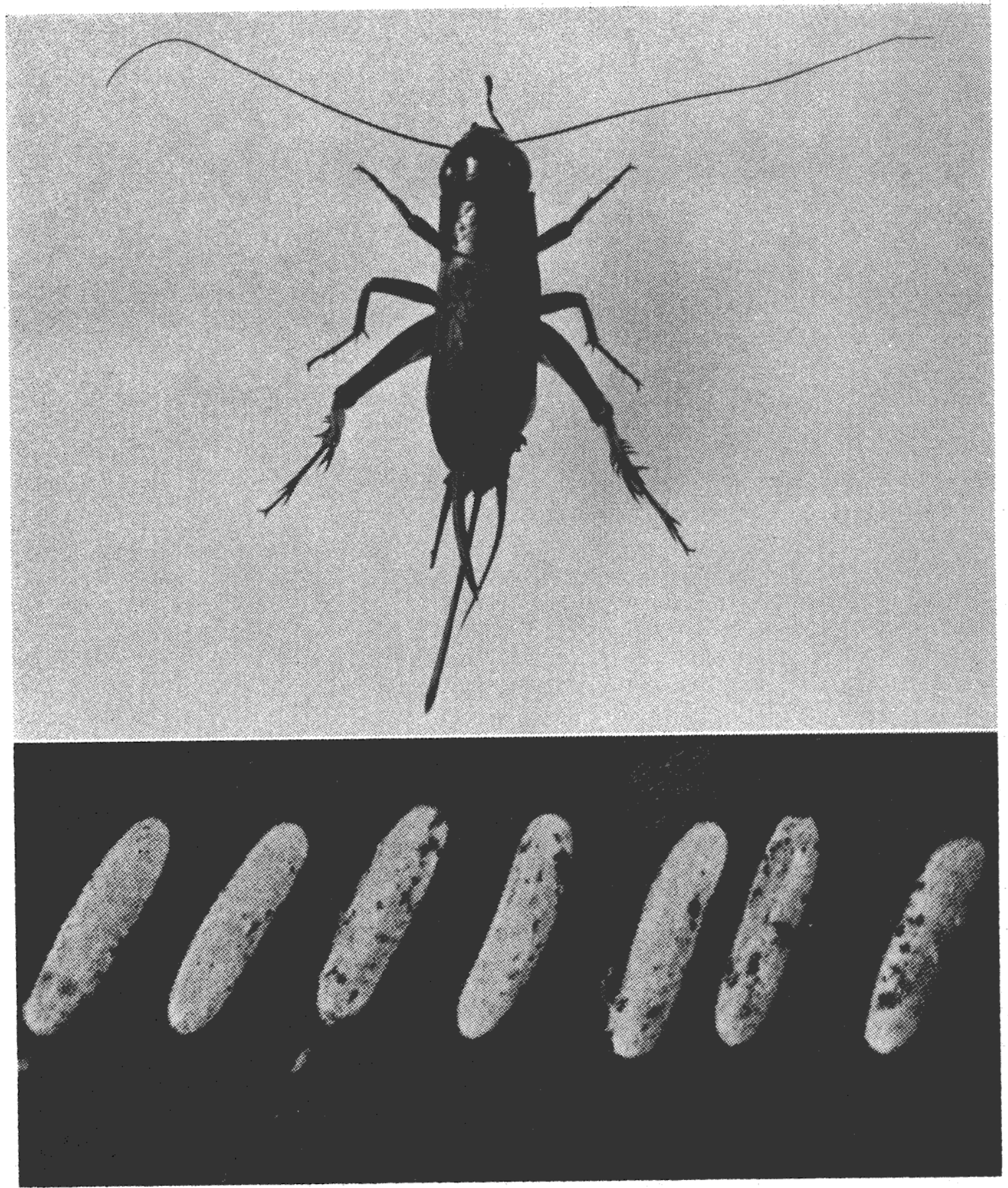

Fig. 4: Black field cricket, Acheta commodus (Walk.)

Top: Adult (X1.3)

Bottom: Eggs dissected from soil (×9.4) [After Atkinson et al.]

\section{BLACK BEETLE \\ Heteronychus sanctae-helenae Blanch.}

This insect is known to occur only in certain parts of the northern half of the North Island, particularly in coastal areas where it has become an established pasture pest. It is also known from St. Helena, several parts of South Africa, in East Africa, Abyssinia, Madagascar and in New South Wales, Australia. It was first recorded in New Zealand on Waiheke Island, Auckland, in March, 1937.

The adult is a glossy black beetle. It is robust in build and measures slightly more than $1 / 2$ in. long. The insect overwinters in this form. Overwintering adults are relatively inactive and remain in this condition in the soil from June to September. Although it 


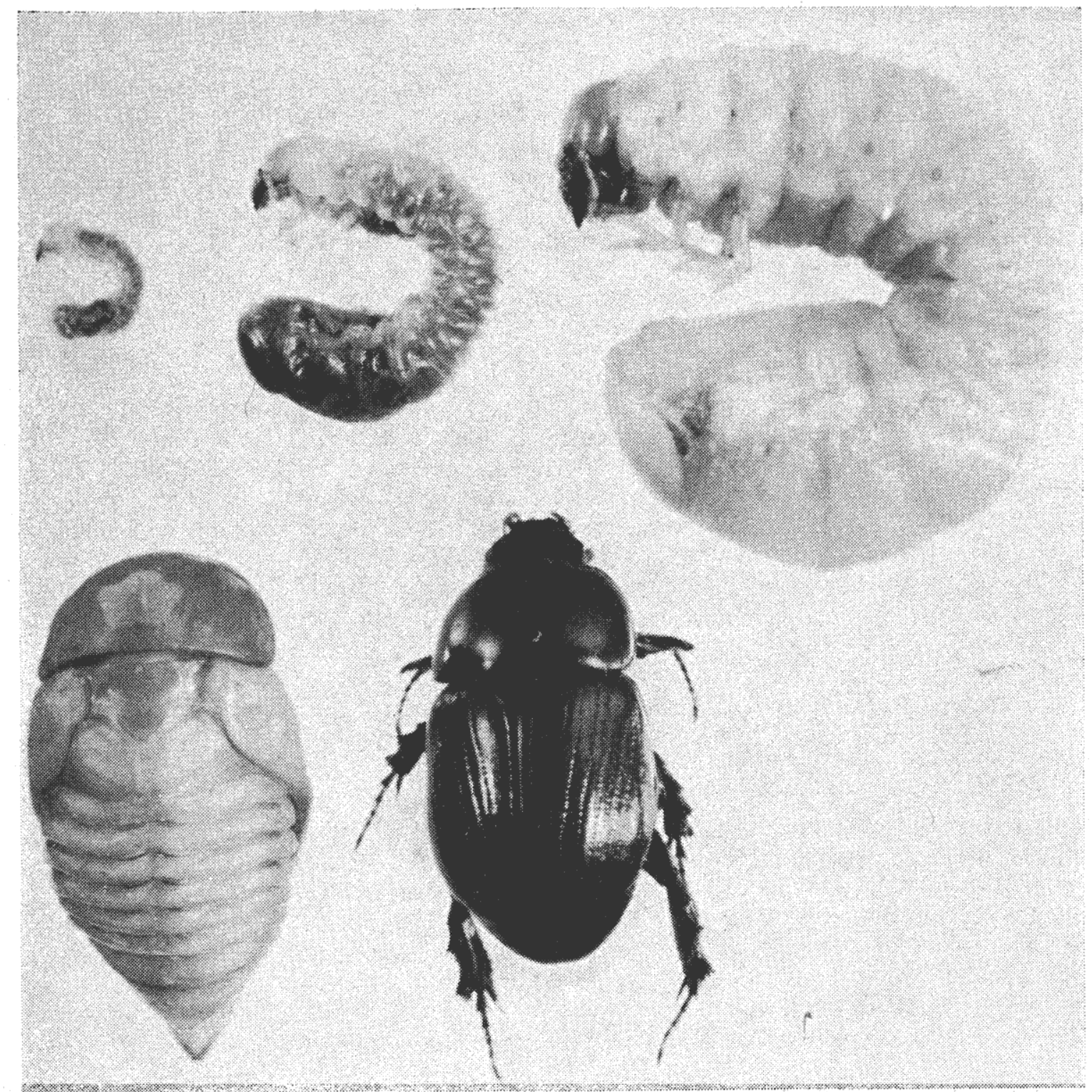

After Todd

Fig. 5: Black beetle, Heteronychus sanctae-helenae Blanch.

Top row: Successive larval stages $(\times 3)$

Bottom left: Pupa $(\times 3)$

Bottom right: Adult $(\times 3)$

has been observed only infrequently, it is apparent that mating takes place in the soil during spring. Eggs may be found in the soil from mid-October to January.

The egg is at first ovoid, white to creamy-white in colour, and about $1 / 12 \mathrm{in.} \mathrm{long.} \mathrm{They} \mathrm{are} \mathrm{laid} \mathrm{singly} \mathrm{and} \mathrm{are} \mathrm{usually} \mathrm{found}$ approximately $1 / 2$ in. below ground level, although in some cases they have been found at a greater depth. Owing to absorption of moisture during incubation, the egg swells and becomes significantly larger and more spherical before hatching. 'The incubation period is about six weeks early in the season but this period probably decreases later when soil temperatures become higher.

The larvae or grubs pass through three stages in the soil. There is a peak for the first stage or instar at mid-December; the peak for the second stage is mid-January, and for the third approximately mid-February. The larva or grub is similar to the grass-grub, having the same habit of lying in the soil in a curled-up position, but it attains a greater size and is about $1 \mathrm{in}$. long when fully grown. The 
head is light brown, the body creamy-white or greyish-white except for the hind segments which appear black where the contents of the hind-gut show through the body wall. Fully grown final instar larvae are uniformly creamy-white in colour owing to evacuation of gut content prior to pupation.

The larvae feed an inch or so beneath the soil surface. They feed on organic matter in the soil but there is no doubt that they also feed on grass roots, as has been amply demonstrated. This feeding, in cases of sufficiently heavy infestation, destroys the rooting system so thoroughly that large areas of turf can be rolled back like a carpet - this is also, of course, a characteristic of grass-grub damage.

The pupa can be found in the soil from January to April, with a peak in March and a few stragglers found up until October. When first formed, the pupa is pale yellow but it changes to reddish-brown before the adult emerges. Work has not been done to determine the exact length of the pupal period but it is probably in the vicinity of 2 to 3 weeks. The new generation beetles emerge through March, April and May. These beetles are present through the following months but by June most of them have become dormant and they remain in this condition throughout the winter. In the spring they resume feeding and continue to feed until December, after which month there is a gradual decline in numbers as they die off. It is usual to find many dead beetles on the ground at this time of the year, and every few live beetles can be found until the new generation begins to emerge. There is only the one generation each year, and during the twelve-months' cycle old-generation beetles are feeding from late September until December and new-generation beetles from March until June, a total feeding period of six months. The principal feeding period of the larvae is from December until February and in some cases may even continue on into March. Because of varying climatic conditions and seasonal trends, there are probably some variations in the life-cycle of the black beetle from one season to another and from place to place.

\section{STEM WEEVIL}

Hyperodes bonariensis Kusch.

This weevil is very small. It is approximately $1 / 10 \mathrm{in.} \mathrm{long} \mathrm{with}$ a very distinct snout, and is grey in colour. Often the insect is covered with soil debris and this renders it difficult to see the true colour. Weevils are active both by day and night and have been observed to feed during the day when the sun was obscured by clouds but their feeding is mainly nocturnal. Mating flights occur during bright sunlight and these have been noted at sea-level and up to over $4,500 \mathrm{ft}$ in tussock areas. Because of their being coated with soil, weevils are often difficult to pick up by the naked eye. In addition, when disturbed, they often "play possum" for seldom less than 20 minutes and up to 45 minutes with the result that they resemble small particles of soil. In heavy infestations populations of over 28 per square foot have been found by slowly flooding soil samples with water from below in trays in the laboratory, but in the field it was not often that more than two adults could be observed in the same sample. If an average of 1 to 2 per square foot can be seen during the day, the actual infestation is a severe one and probably over 20 per square foot.

During the winter the species is present in the adult stage and these start to lay eggs in the spring at the beginning of September. The eggs are greenish-black and bean-shaped. During oviposition (in moist fleshy tissue that was usually green but occasionally brownish) 


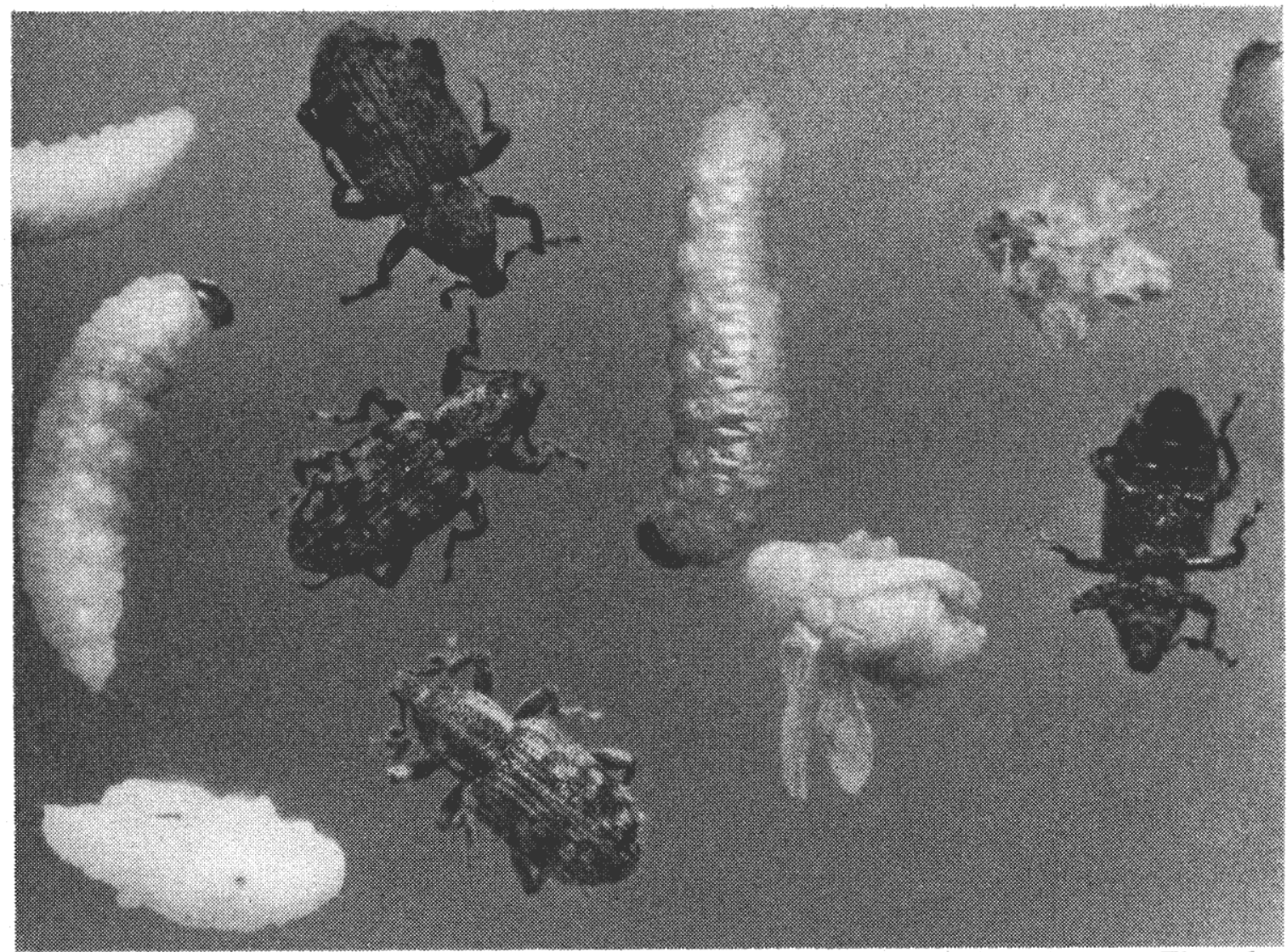

Photo E. Thornley

Fig. 6: Stem weevil, Hyperodes bonariensis Kuschel. Adults, larval and pupae $(\times 10)$

adults made a pocket in leaf-sheath tissue, always from the back of leaf sheaths where they closely adhered to tillers. These pockets never extend to the next leaf or stem and no eggs are laid between sheath and stem. In each pocket only one aperture was made and two eggs were laid, usually end to end, but occasionally there was only a single egg or three eggs to a pocket. Most eggs were inserted from $1 / 8$ to $1 / 4 \mathrm{in}$. below leaf "collars" but occasionally up to $1 \mathrm{in}$. below. Though many eggs. were found in the leaves closest to the ground, some were as high as the sixth leaves from the crown of the plant, though this was still not more than $2 \mathrm{in}$. from ground level. Eggs may be found in the field from July to mid-November. The incubation period for eggs is 12 to 14 days in the laboratory but in the field this period is apparently longer, the minimum recorded being 23 days.

When eggs hatched, the larvae always tunnelled leaf sheaths for a while and always made their way downwards. After this, however, there was no consistency. Some may remain in leaf sheaths until they reach points of attachment to tillers and complete development there; others, after a short distance in leaf sheaths, may enter the centres of tillers between nodes; others may enter tillers at or just above the nearest nodes while some work round the outside of nodes. Larvae entering one node almost invariably remain in that internode in the case of plants producing seed heads, but in the case of young plants larvae nearly always moved downwards into crowns of plants irrespective of the presence or absence of nodes. In the presence of seed-heads, larvae enter near any of the nodes from the 2 nd to seventh from the crowns. Initially these insects moved upwards but later they moved down again as they approached the fully-fed state. Tunnelling in stems caused "white heads". At this time of year larvae could be found from early October to mid-December. 
When fully-fed, larvae cut holes in tillers or straws and drop to the ground where they seek shelter under plant cover. Pupation occurs in the soil up to a depth of $1 / 4$ in. and pupae of this generation occur from the last week in November to mid-January.

After 7 to 15 days, adult weevils emerge and are present in the field from the beginning of December to the end of February. A new cycle is then started, eggs being present in the field from about mid-December until the end of March, larvae from midJanuary to the end of April, pupae from the beginning of March to mid-May and adults from early March to the end of November.

This cycle was worked out in Canterbury. The only major variation from this pattern is that, in some years, about once in four years, there is the appearance of a third generation.

This weevil is generally distributed over the North and South Islands. Larvae will feed on short-rotation (H1), Italian and perennial ryegrasses, cocksfoot, sweet vernal, Chewings fescue, wheat, oats and barley, but it is to the first two - short-rotation and Italian ryegrasses - that severe damage is caused. There are several types of damage:

(1) Damage by adults produces a silvery appearance on grass leaves. It is confined mostly to the tips of leaves but may be so serious that whole leaves may be destroyed in local patches.

(2) Damage by larvae is the most severe type, and is caused by the boring of larvae in tillers of the plant. In young pasture, without seed-heads, larvae move downwards into the crowns of the plants and even one larva per tiller may be enough to cause wilting, then browning and finally death of plants. As a result, large areas of grass may die out and grass grub may be suspected; however, inspection of the roots will reveal these to be uneaten.

(3) Injury to seed-heads is caused because larvae always move up into the stems of seed-heads and produce "white heads" that do not set seed. This injury by itself is generally not of much importance.

\section{SOLDIER FLY}

Altermetoponia rubriceps Macq.

This Australian insect was first recorded in New Zealand by Muggeridge in 1944 in the Opotiki district. It has been taken since from Whakatane, the neighbourhood of Matamata, and around Auckland.

The adult is a slender two-winged fly, from $1 / 4$ to $3 / 8 \mathrm{in}$. long, males being considerably shorter than females. It is black in colour with a red head, and the wings have a distinctly dusky tinge. The larva is approximately $2 / 5$ in. long when full grown and is a dusky creamy or whitish colour. It does not have biting mouthparts but is said to suck sap from the roots of plants, including grasses.

Not enough detailed work has yet been done in New Zealand to give a complete picture of the life-history here. Studies in the neighbourhood of Sydney, Australia, show that there are two flight periods of the adult insect. Adults were reared during October to December from larvae collected in May and August and another lot of adults emerged in April from larvae collected in November. Adults were present in the field from early April to mid-May.

Females deposit elongate-oval opaque white eggs a day or two after emergence. They are laid in the soil near the surface and hatch in 2 to 3 weeks. Small larvae may be found throughout the year, and while there is no definite evidence as to the length of 


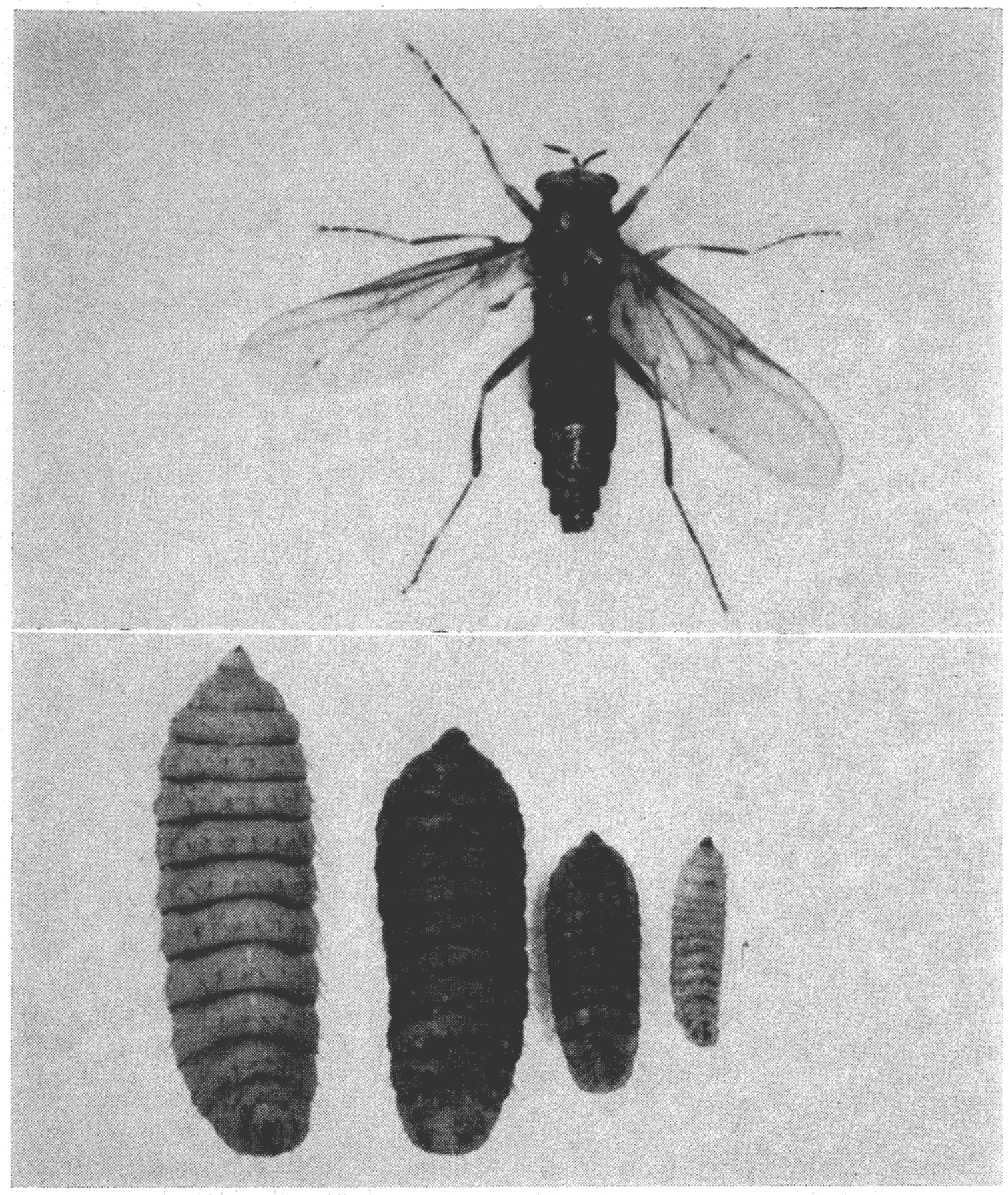

Photo M. E. Soulsby

Fig. 7: Soldier fly, Altermetoponia rubriceps (Macq.)

Top: Adult $(\times 5)$

Bottom: Different stages of the larva $(\times 5)$

the larval period, it seems likely that this is at least six months and possibly twelve months. Pupation occurs just below the soil surface and seems to occupy at least 18 days. In the Opotiki area, adults have been recorded during March and April and there has been one case where a fly emerged in November. Whether there are two races of the insect, one emerging in spring and the other in autumn, is not known. It is thought more likely that the main emergence is in the autumn and that those flies that emerge in spring are delayed individuals that should have emerged the previous autumn.

There is some uncertainty as to whether the larvae really damage grass. This uncertainty is possibly brought about by the feeding 
habits. The larvae do not chew, but probably rasp and suck the issuing sap from the roots. Nevertheless, they occur in large numbers in infested pasture (150 per square foot) and during a recent survey it was found that, in pasture where these sorts of populations were present, the ryegrass content was very low, the pasture containing largely flat weeds, Poa trivialis and Paspalum. It was noted in one area of inspection that potash had given good results in infested grassland; the topdressed area stood out green in very marked contrast to the rest of the pasture. However, with the establishment of a substation of the Entomology Division, D.S.I.R., at Auckland, work has been planned, and it is hoped to make progress with this problem.

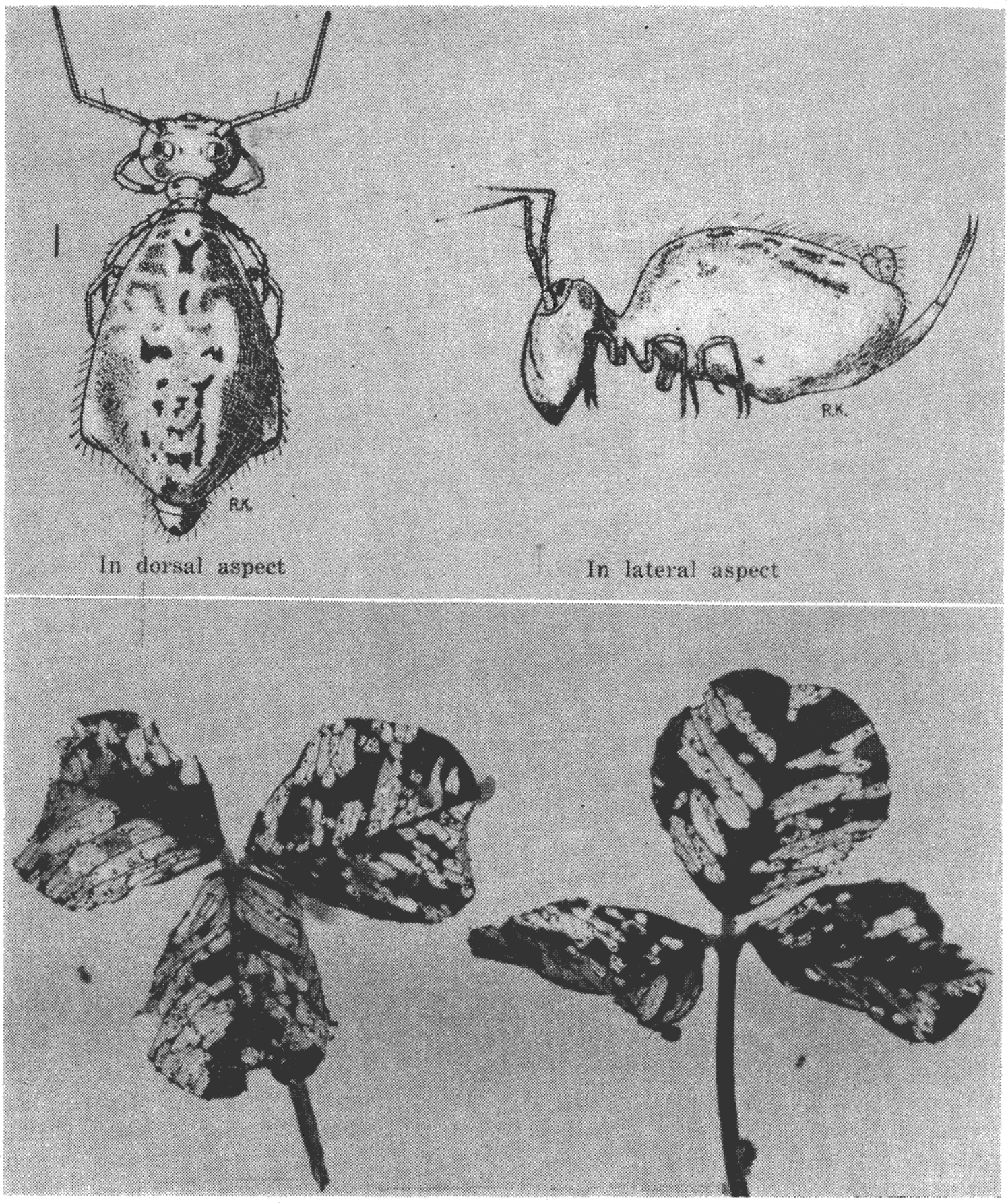

Fig. 8: Lucerne flea, Smynthurus viridis (L.)

Top:Adults $(\times 9)$ [After Evans]

Bottom: Clover leaves damaged by lucerne flea (enlarged) [After Atkinson et al.] 


\section{LUCERNE FLEA \\ Smynthurus viridis (L.)}

This insect has been recorded in New Zealand since 1929. It has been taken in many districts of the North Island - e.g., in the Manawatu, Auckland and Hawke's Bay - and in South Canterbury, Otago and Southland districts.

The lucerne flea is a biting insect. It prefers the soft green tissue of the leaves and it eats or chisels off the green portions leaving the veins and cuticle. Attacked foliage thus assumes a bleached appearance and damaged herbage is greatly reduced in feed value.

The preferred hosts are legumes, particularly clovers and lucerne. The insect will also feed on grasses occurring in swards where the preferred hosts are being attacked.

In New Zealand the lucerne flea has not so far caused sufficient damage to warrant the application of control measures. In parts of Auckland and Hawke's Bay, a certain amount of injury to clovers in pastures has periodically appeared. This has occurred mostly in fields shut up for hay, but generally conditions in New Zealand are not favourable to widespread or serious attacks.

The adult insect is approximately $3 / 16$ in. long. It is green or yellowish-green with some darker patches and is globular in shape. It is wingless and on the underside of the body there is a springing apparatus which the insect uses to jump vigorously when disturbed. This habit of suddenly springing gives these insects the common name of "springtails". The immature forms are similar in appearance to the adults except, of course, that they are smaller.

Eggs are laid on the soil in little batches or heaps. The minute egos are covered with a secretion containing soil that has passed through the alimentary system of the insect. Air temperatures soil moisture, and the physical and chemical nature of the soil influence egg laying. Very low and very high temperatures are unfavourable, as are soils that are dry, sandy or alkaline. At fairly high temperatures, up to $77^{\circ} \mathrm{F}$, and provided the soil moisture content is adequate, eggs will hatch in eight days. They are capable of surviving unfavourable low or high temperatures and extreme dryness for a period of several months and when conditions become suitable they will hatch. The progress of the hatched nymphs depends on suitable conditions of high atmospheric humidity and adequate temperature; at mean monthly temperatures of $50^{\circ} \mathrm{F}$ nymphs become adult in approximately 50 days, and at approximately $60^{\circ} \mathrm{F}$, in 30 days.

\section{WHITE-FRINGED WEEVIL Graphognathus leucoloma (Boh.)}

This weevil is a native of South America and it is believed to have been introduced into New Zealand about 1940 with U.S. war equipment. It was first discovered in New Zealand in North Auckland about 1944. Since then it has spread to other North Island areas where it frequently occurs in pest proportions. In this country it has been taken feeding on pasture species, exotic forest seedlings lucerne, peas, tomatos, potatoes, barley, and crucifers. Although the importance of the insect in pastures in New Zealand has not yet been fully determined, there is strong evidence to suggest that it is becoming a major problem in these situations.

The larval stages of the insect feed on plant roots and are generally responsible for most of the damage. Affected plants will wilt and turn yellow before dying. The adults, which are all females and cannot fly, do some damage by feeding on foliage. The insect 


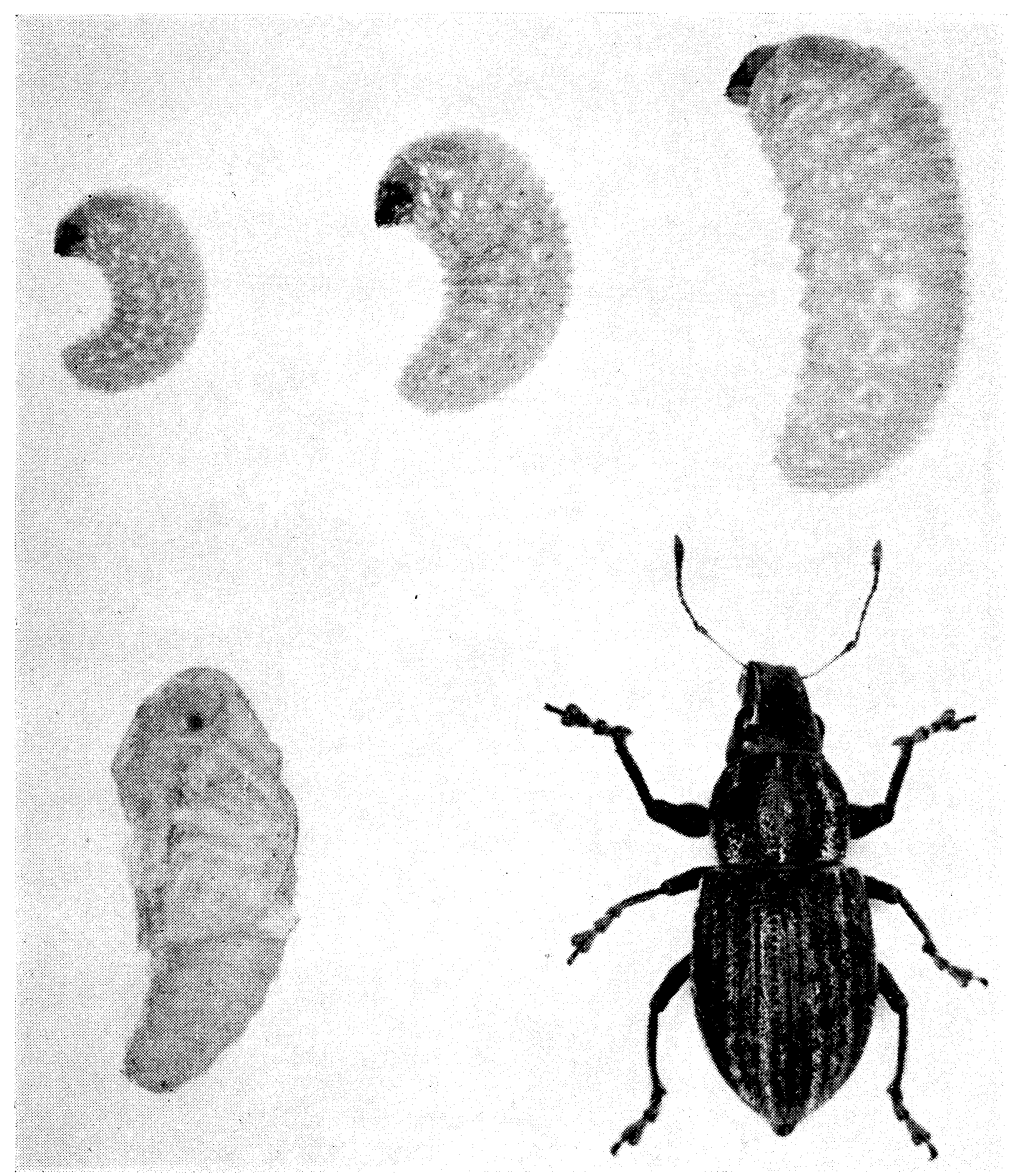

Photo M. E. Soulsby

Fig. 9: White-fringed weevil, Graphognathus leucoloma (Boh.)

Top row: Successive stages of the grub or larva $(\times 4)$

Bottom left: Pupa $(\times 4)$

Bottom right: Adult $(\times 4)$

does not cause uniform damage over large continuous areas. Generally damage ranges from a trace in one part of a field to the destruction of another part. Dispersal of the pest may occur in a numbers of ways. Although the insect is incapable of flying, eggs are deposited on many plants that are moved in commerce. Larvae may be transported in small quantities of soil, and the adults, which have a pronounced tendency to climb upwards, readily cling to objects being transported.

A study of the insect under New Zealand conditions indicates that it has a two-year life-cycle and that the larvae pass through four or possibly 5 instars before pupating. As the result of overlapping generations; larvae at various stages of development may be found in the ground throughout the year. Adults emerge from 
about D̂̃ecember until Ápril with peak numbers occurring during January. The females reproduce parthenogenetically and may lay many hundreds of eggs.

The eggs are deposited in clusters in gelatinous masses on such objects as stones and sticks, and on the bases of plants. On account of the soil adhering to the egg masses, they are extremely difficult to detect. It is apparent that moist conditions are necessary for hatching and that the incubation period may last several months when conditions are dry. The larvae, which are legless, are found entirely below ground level where they feed mainly on the taproot of the host plant. Current evidence indicates that complete larval development takes approximately 16 to 18 months from about May until the following October.

\section{ACKNOWLEDGEMENTS}

Much information concerning armyworm has been supplied by Dr J. S. Timlin; D. H. Todd has similarly supplied information on the white-fringed weevil.

\section{LITERATURE USED IN THE COMPILATION OF THIS PAPER}

Atkinson, J. D. Brien, R. M. Chamberlain, E. E.; Cottier, W.; Dingley, J. M.; Jacks, H.; Reid, W. D.; Taylor, G. G. 1956: Plant Protection in New Zealand. Tech. Corres. School, N.Z. Dept. of Education. 699 pp.

Dumbleton, L. J. 1938: The Lucerne Flea (Smynthurus viridis) in New Zealand. N.Z. J. Sci. Tech., 20A: 197A-211A.

1945: Contribution to the Ecology of Oxycanus cervinata Walk. N.Z. J. Sci. Tech., 27A: 114-28.

1949: The Economic Status of Metoponia rubriceps Macquart. N.Z. J. Sci. Tech., 30B: 224-32.

Kelsey, J. M. 1952: Grass-grub and Grass Caterpillar Control. Bull. No. 244, N. Z. Dept. of Agriculture: $20 \mathrm{pp}$.

1958: Damage in Ryegrasses by Hyperodes griseus Hust. N.Z. J. Agric. Res., 1: 790-5.

Todd, D. H. 1959: Black Beetle, Heteronychus sanctae-helenae Blanch. in Pastures in New Zealand. N.Z. J. Agric. Res., 2: 126273. 